\title{
Evaluation of Technology Change Effects on Quantitative Assessment of Water, Energy and Food Nexus
}

\author{
Ali Karnib \\ Lebanese University, Hadath Campus, Baabda, Lebanon \\ Email:karnib.ali@gmail.com
}

How to cite this paper: Karnib, A. (2017) Evaluation of Technology Change Effects on Quantitative Assessment of Water, Energy and Food Nexus. Journal of Geoscience and Environment Protection, 5, 113.

https://doi.org/10.4236/gep.2017.53001

Received: January 13, 2017

Accepted: February 12, 2017

Published: February 15, 2017

Copyright $\odot 2017$ by author and Scientific Research Publishing Inc. This work is licensed under the Creative Commons Attribution International License (CC BY 4.0).

http://creativecommons.org/licenses/by/4.0/

\begin{abstract}
The quantitative assessment framework of the water, energy and food (WEF) nexus proposed by [1] permits the analysis of the WEF as an interconnected system of resources that directly and indirectly affect one another. The model performs simulation of policy options and scenarios that respond to quantitative variations of the use of WEF resources. One of the key outcomes of the mathematical formulation of the model is the WEF nexus intersectoral technology matrix. In order to take advantages and analyzing policy options of adopting high efficient intersectoral use technologies, WEF intersectoral use intensities and intersectoral allocation coefficients are introduced to the technology matrix of the nexus model proposed in [1]. The developed method is then applied to evaluate the WEF nexus case study of Lebanon. Lastly, the conclusions and further developments are presented.
\end{abstract}

\section{Keywords}

Water Energy Food Nexus, Technology Changes, Sustainable Development

\section{Introduction}

The important interactions between water energy and food are imposing new challenges to research and scientific modelling, especially that these resources are driven by many same key drivers, such as population growth, urbanization, mobility, economic development, climate change, technology modifications, governance, market, regulations and international trade [1]-[6]. Quantitative nexus approaches will certainly provide effective support for the communication between science and sustainable water energy food policies [1] [2] [7] [8]. The development of nexus tools for analyzing impacts of the above mentioned drivers on WEF resources is one of today's key challenges [9]-[16]. A practical and ma- 
thematically-based quantitative assessment framework of the WEF nexus is newly proposed by [1] (Q-Nexus Model). The methodological approach presented in [1] performs simulation of policy options and scenarios that respond to quantitative variations of the WEF resources. However, the simulation of policy options by considering the use of high efficient technologies necessitates methodological addition to the Q-Nexus Model.

This paper presents methodological supplement to the model presented in [1] to analyze policy options and scenarios of adopting efficient intersectoral use technologies. This will allow analysing scenarios of changing the technology matrix $(A)$ by considering "Best Practice" and "High Efficient" technological alternatives.

\section{Summary of the WEF Nexus Model Introduced in [1]}

A quantitative assessment framework of the WEF nexus is proposed in [1]. This model is built on flexible structure to take into account variations related to local, national and regional particularities as well as being able to perform quantification, scenarios analysis and optimization, all in one integrated approach. The structure of the Q-Nexus Model is built on input-output theory and it is based on the quantitative balance of the WEF total quantities through two main conceptual elements: 1 ) the intersectoral use quantities $(Z)$ and 2 ) the end use (or final demand) quantities $(y)$. The sum of these two components gives the total resources quantities $(x)$, therefore, the balance quantitative equation will be as follows:

$$
Z+y=x
$$

The end use quantities $(y)$ are those used in the socio-economic system which cover households demands, government demands, rest of the economy demands, losses, accumulation (storage) and exports.

A set of inflows were identified to represent the WEF sectors, for example, surface water, groundwater, desalination, wastewater and drainage water reuse inflows covering the water sector, imported petroleum and all types of electricity including renewable energy, covering the energy sector, and irrigated cereals, irrigated roots and other food production items covering the area of food.

It is important to mention that these inflows are particularly identified for the Lebanese case study presented in [1], the organisation of these elements could change to take into account diversification related to local, national and regional particularities.

A set of equations are developed in [1] to mathematically shape the Q-Nexus Model. In addition to the three variable elements $(Z),(y)$ and $(x)$, one of the key outcomes of the mathematical formulation of the model is the expanded intersectoral intensity coefficients matrix (may be referred also as "the intersectoral technology matrix"). This matrix is one of the main variables of the model because it represents the identity of the nexus system and it is constructed as follows:

If we denote by: 
$n$ : number of water resources inflows (i.e. surface water, groundwater, desalination...);

$m$ : number of energy resources inflows (i.e. petroleum, natural gas, electricity, renewable energy...);

$h$ : number of food resources inflows (i.e. irrigated crop, animal production, fisheries...);

$z_{i j}^{w_{-} e}$ : the use of $i^{\text {th }}$ water resource inflow in the $j^{\text {th }}$ energy resource inflow;

$Z_{i j}^{w_{-}}{ }^{f}$ : the use of $i^{\text {th }}$ water resource inflow in the $f^{\text {th }}$ food resource inflow;

$z_{i j}^{e_{-} w}$ : the use of $i^{\text {th }}$ energy resource inflow in the $j^{\text {th }}$ water resource inflow;

$Z_{i j}^{e}$-e $^{e}$ : the use of $i^{\text {th }}$ energy resource inflow in the $j^{\text {th }}$ energy resource inflow;

$z_{i j}^{e_{-} f}$ : the use of $i^{\text {th }}$ energy resource inflow in the $f^{\text {th }}$ food resource inflow;

$Z_{i j}^{f-e}$ : the use of $i^{\text {th }}$ food resource inflow in the $f^{\text {th }}$ energy resource inflow;

$Z_{i j}^{f-f}$ : the use of $i^{\text {th }}$ food resource inflow in the $f^{\text {th }}$ food resource inflow.

The expanded intersectoral intensity coefficients of the water energy food nexus system are defined as follows:

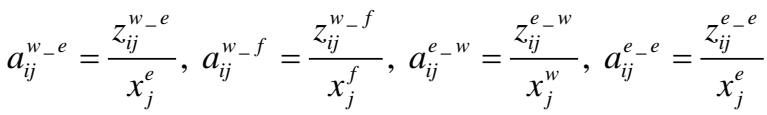

$$
\begin{aligned}
& a_{i j}^{e-f}=\frac{z_{i j}^{e}-f}{x_{j}^{f}}, a_{i j}^{f-e}=\frac{z_{i j}^{f}-e}{x_{j}^{e}}, a_{i j}^{f-f}=\frac{z_{i j}^{f-f}}{x_{j}^{f}}
\end{aligned}
$$

where $x_{j}^{w}, x_{j}^{e}, x_{j}^{f}$ are the total use of the $j^{\text {th }}$ water resource inflow, total use of the $j^{\text {th }}$ energy resource inflow and total use of the $j^{\text {th }}$ food resource inflow, respectively.

In block matrix form:

$$
A=\left[\begin{array}{ccc}
0 & A^{w_{-} e} & A^{w_{-} f} \\
A^{e_{-} w} & A^{e_{-} e} & A_{-}^{e_{-} f} \\
0 & A^{f_{-} e} & A^{f_{-} f}
\end{array}\right]
$$

where $A$ is the WEF nexus technology matrix.

The water for water and food for water relationships are considered quantitatively negligible, so they are set equal to zero.

In terms of nexus quantification, when the intersectoral and end use values are constructed, then we can start evaluating scenarios, for example, what if we produce more food, what if there will be droughts, what if we reduce losses and wastes, and so forth.

The total outputs $(x)$ caused by end use quantities $(y)$ are related by the following equations $[1]$ :

$$
x=L y
$$

and

$$
L=(I-A)^{-1}
$$

where $I$ is the identity matrix.

The whole core of the WEF nexus is contained in the matrix $L$. It is easy to examine the changes in all elements in the intersectoral WEF use quantities $(Z)$ caused by $(y)$ [1]. 
The first type of simulation that could be performed using the Q-Nexus Model consists of assuming variations of the end use values represented in the model by the $(y)$ vector. These scenarios are analyzed for any planned policy related to increasing of resources demand or reducing losses. A second type of simulation could be also performed using the model by analyzing scenarios of changing the technology matrix $(A)$ by considering "High Efficient" and "Best Practice" technology matrix alternatives. However, this necessitates a methodological addition to the model presented in [1] to analyze policy options of adopting high efficient intersectoral use technologies. This issue will be addressed in Section 3.

\section{Upgrading of the Model Presented in [1] to Analyze Technological Change Scenarios}

The WEF "High Efficient" or "Best Practice" intersectoral use technologies can be defined as those for which the ratios of the intersectoral quantities used to produce one unit of resource are relatively low.

If we denote by:

$z_{j}^{w} \perp^{e}=\sum_{i=1}^{n} z_{i j}^{w}-^{e}$ the water use in the $f^{\text {th }}$ energy inflow;

$z_{j}^{w_{-} f}=\sum_{i=1}^{n} z_{i j}^{w_{-} f}$ the water use in the $j^{\text {th }}$ food inflow;

$z_{j}^{e_{-}-w}=\sum_{i=1}^{m} z_{i j}^{e_{-}-w}$ the energy use in the $j^{\text {th }}$ water inflow;

$z_{j}^{e_{-} e}=\sum_{i=1}^{m} z_{i j}^{e_{-} e}$ the energy use in the $j^{t^{t h}}$ energy inflow;

$z_{j}^{e_{-} f}=\sum_{i=1}^{m} z_{i j}^{e_{-} f}$ the energy use in the $f^{\text {th }}$ food inflow;

$z_{j}^{f-e}=\sum_{i=1}^{h} z_{i j}^{f}-^{e}$ the food use in the $f^{\text {th }}$ energy inflow;

$z_{j}^{f_{-} f}=\sum_{i=1}^{h} z_{i j}^{f_{-} f}$ the food use in the $j^{\text {th }}$ food inflow.

The WEF intersectoral use intensities $(t)$ and intersectoral allocation coefficients $(c)$ are proposed to be integrated within the "technology matrix", these two policy aspects are defined as follows:

1) WEF intersectoral use intensities $(t)$ :

WEF intersectoral use intensities $(t)$ (may be referred also as footprints) were selected because they are able to refer to the efficiency of the intersectoral use technologies. The lower the value of resources use intensities (or footprints), the better the resources usage in the production of other resources inflows.

The WEF intersectoral use intensities $(t)$ are calculated as follows:

Intensity of water use in the $f^{\text {th }}$ energy inflow:

$$
t_{j}^{w_{-} e}=\frac{z_{j}^{w_{-} e}}{x_{j}^{e}}
$$

Intensity of water use in the $f^{\text {th }}$ food inflow:

$$
t_{j}^{w_{-} f}=\frac{z_{j}^{w_{-}} f}{x_{j}^{f}}
$$

Intensity of energy use in the $f^{\text {th }}$ water inflow:

$$
t_{j}^{e_{-} w}=\frac{z_{j}^{e_{-} w}}{x_{j}^{w}}
$$


Intensity of energy use in the $f^{\text {th }}$ energy inflow:

$$
t_{j}^{e_{-} e}=\frac{z_{j}^{e_{-} e}}{x_{j}^{e}}
$$

Intensity of energy use in the $f^{\text {th }}$ food inflow:

$$
t_{j}^{e_{-} f}=\frac{z_{j}^{e_{-} f}}{x_{j}^{f}}
$$

Intensity of food use in the $j^{\text {th }}$ energy inflow:

$$
t_{j}^{f_{-} e}=\frac{z_{j}^{f_{-} e}}{x_{j}^{e}}
$$

Intensity of food use in the $f^{\text {th }}$ food inflow:

$$
t_{j}^{f_{-} f}=\frac{z_{j}^{f-f}}{x_{j}^{f}}
$$

The WEF intersectoral use intensities $t$ represent the effectiveness of the nexus system and they could be used to compare the performance of different WEF nexus systems. Moreover, the intensities $t$ will serve to identify sustainable policy options by evaluating and analyzing the effects of technology changes on quantitative assessment of WEF nexus. For instance, the effect of the replacement of gravity irrigation with pressurized irrigation system, which achieve water savings and require more energy, could be analyzed by changing the corresponding water and energy use intensities.

The construction of the technology matrix based on the best practice WEF intersectoral use intensities will be addressed in the subsequent paragraphs.

2) WEF intersectoral allocation coefficients (c):

The WEF intersectoral allocation coefficients are defined as follows:

$$
\begin{aligned}
& C_{i j}^{w_{-} e}=\frac{z_{i j}^{w_{-} e}}{z_{j}^{w_{-} e}}, C_{i j}^{w_{-} f}=\frac{z_{i j}^{w_{-} f}}{z_{j}^{w_{-} f}}, C_{i j}^{e_{-}{ }^{w}}=\frac{z_{i j}^{e_{-} w}}{z_{j}^{e_{-} w^{w}}}, C_{i j}^{e_{-} e}=\frac{z_{i j}^{e_{-} e}}{z_{j}^{e_{-} e}} \\
& c_{i j}^{e_{-} f}=\frac{z_{i j}^{e_{-} f}}{z_{j}^{e_{-} f}}, c_{i j}^{f_{-}}{ }^{e}=\frac{Z_{i j}^{f-e}}{z_{j}^{f-e}}, c_{i j}^{f_{-} f}=\frac{z_{i j}^{f-f}}{z_{j}^{f-f}}
\end{aligned}
$$

In block matrix form:

$$
C=\left[\begin{array}{ccc}
0 & C^{w_{-} e} & C^{w_{-} f} \\
C^{e_{-} w} & C^{e_{-} e} & C^{e_{-} f} \\
0 & C^{f_{-} e} & C^{f_{-} f}
\end{array}\right]
$$

where $C$ is the WEF intersectoral allocation matrix. WEF nexus intersectoral allocation policies vary from one system to another. Each country is characterized by specific WEF nexus system in accordance to its natural, social, economic and governance conditions.

The two coefficients $t$ and $c$ are introduced to Equations (2)-(8) as follows:

$$
\begin{aligned}
& a_{i j}^{w_{-} e}=c_{i j}^{w_{-} e} * t_{j}^{w_{-} e} \\
& a_{i j}^{w_{-} f}=c_{i j}^{w_{-} f} * t_{j}^{w_{-} f} \\
& a_{i j}^{e_{-}{ }^{w}}=c_{i j}^{e_{-}{ }^{w}} * t_{j}^{e_{-}{ }^{w}}
\end{aligned}
$$




$$
\begin{gathered}
a_{i j}^{e_{-} e}=c_{i j}^{e_{-} e} * t_{j}^{e_{-} e} \\
a_{i j}^{e_{-} f}=c_{i j}^{e_{-} f} * t_{j}^{e_{-} f} \\
a_{i j}^{f-e}=c_{i j}^{f-e} * t_{j}^{f-e} \\
a_{i j}^{f-f}=c_{i j}^{f-f} * t_{j}^{f-f}
\end{gathered}
$$

In block matrix form:

$$
A=\left[\begin{array}{ccc}
0 & A^{w_{-} e} & A^{w_{-} f} \\
A^{e_{-} w} & A^{e_{-} e} & A^{e_{-} f} \\
0 & A^{f_{-} e} & A^{f-f}
\end{array}\right]=\left[\begin{array}{ccc}
0 & C^{w_{-} e} t^{\hat{w_{-}} e} & C^{w_{-} f} t^{w_{-} f} \\
C^{e_{-} w} t^{e_{-} w} & C^{e_{-} e} \hat{t^{e_{-} e}} & C^{e_{-} f} t^{e_{-} f} \\
0 & C^{f_{-} e} \hat{t^{f_{-} e}} & C^{f_{-} f} \hat{t_{-} f}
\end{array}\right]
$$

where $\hat{t}$ is the diagonal matrix with the elements of the $t$ vector along the main diagonal.

Analyzing scenarios of changing the technology matrix $(A)$ by considering "High Efficient" and "Best Practice" technology matrix alternatives could be performed using the developed equations. Assuming that the WEF intersectoral allocation policies (as represented in $C$ matrix) do not change, the quantitative variations of resources in any WEF nexus system due to the change of the intersectoral use intensities could be evaluated.

If the superscript " 1 " is used to represent the values of variables after the change in intersectoral use and the superscript " 0 " is used to represent the initial situation for values of variables. Assuming that WEF intersectoral allocation policies is unchanged $\left(C^{0}=C^{1}=C\right)$, the new technology matrix $A^{1}$ caused by new WEF intersectoral use intensities $\left(t^{t}\right)$ is then found as in equation 34 .

$$
A^{1}=\left[\begin{array}{ccc}
0 & C^{w_{-} e} t^{1 w_{-} e} & C^{w_{-} f} t^{1 w_{-} f} \\
C^{e_{-}{ }^{w}} t^{1 e_{-} w} & C^{e_{-} e} t^{1 \hat{e}_{-} e} & C^{e_{-} f} t^{1 \hat{e}_{-} f} \\
0 & C^{f_{-} e} t^{1 \hat{\hat{f}_{-} e}} & C^{f-f} t^{1 \hat{f_{-} f}}
\end{array}\right]
$$

the total outputs $\left(x^{I}\right)$ caused by new technology matrix $A^{l}$ are then calculated as in Equation 10.

$$
x^{1}=\left(I-A^{1}\right)^{-1} y^{0}
$$

with this result for $x^{1}$, it is easy to examine the changes in all elements in the intersectoral WEF use quantities ( $Z$ matrix) caused by $A^{1}$. From the definition of intensity coefficients, we find $Z=A^{1} \hat{x}^{l}$ along with $t^{l}$, where $\hat{x}$ is the diagonal matrix with the elements of the vector along the main diagonal.

Moreover, based on the origination of $(t)$ and $(c)$, it became possible interpreting the $A$ matrix to better understand the WEF nexus system and to compare different nexus systems with each other, therefore, the $A$ matrix of the Q-Nexus Model totally befits to be a Nexus Matrix Code or fingerprinting matrix of a nexus system. 


\section{Application and Analysis of Results}

In order to put the introduced method in practice, the data of the WEF nexus case study of Lebanon as presented in [1] will be analyzed. The considered WEF nexus inflows are as follows:

Water inflows (including extraction, treatment, conveyance \& distribution) ( $\mathrm{Mm}^{3} /$ year): 1) surface water $\left.(W 1), 2\right)$ groundwater $\left.(W 2), 3\right)$ desalination $(W 3), 4)$ wastewater reuse $(W 4), 5)$ recycled water and agricultural drainage water reuse $(W 5)$.

Energy inflows (evaluated in terms of primary energy equivalent in ktoe/ year on a net calorific value basis): 1) imported petroleum (E1), 2) electricity (petroleum) $(E 2), 3)$ electricity (hydro) $(E 3), 4)$ imported electricity $(E 4)$, v) electricity (wind/solar) $(E 5), 5)$ biofuels $(E 6)$.

Food inflows (including agriculture, food processing \& transportation) (kt/year): 1) irrigated cereals $(F 1), 2)$ irrigated roots and tubers $(F 1), 3)$ irrigated vegetables $(F 2), 4)$ irrigated fruits $(F 3), 5)$ other Irrigated agriculture $(F 4), 6)$ livestock-meat $(F 5), 7)$ livestock-milk $(F 6), 8)$ livestock-eggs $(F 7), 9)$ fishing and aquaculture production $(F 8), 10)$ rainfed agriculture $(F 9), 11)$ imported agricultural products $(F 10), 12)$ imported livestock products-meat, milk, eggs \& fish (F11).

Table 1 presents the WEF inflows intersectoral use and the corresponding end use for year 2012. There was no biofuel production in 2012 in Lebanon, the use of biomass was limited to final demand for some economic activities or household use. Therefore, the food for energy indicators is not considered in this application.

Water use intensities in energy and food inflows are calculated using equations (12) and (13), the results are presented in Table 2. The results shown in Table 3 are calculated using equations (14) and (16) and account for energy use intensities in water and food inflows. Table 4 shows the results of the food use intensities in energy and food inflows calculated using Equations (17) and (18).

The WEF intersectoral allocation coefficients are calculated using Equations (19)-(25), the results are presented in Table 5.

A scenario of replacing of gravity surface irrigation with pressurized irrigation systems for some irrigated crops is analyzed. This scenario will achieve water savings (reduction of water use intensities for some food inflows) and will require more energy. The projected water and energy intersectoral use intensities are shown in Table 6 and Table 7. Using the proposed method, it becomes easy to evaluate the new intersectoral and total outputs from the water, energy and food sectors based on this new intersectoral use intensities. In this scenario we assume that the WEF intersectoral allocation matrix (as represented in the $C$ matrix) and the end use (as represented in the $y$ vector), are unchanged. Table 8 presents the resulted nexus technology matrix for the considered scenario calculated using Equation (35).

The resulting changes in intersectoral quantities $(\Delta z)$ caused by the change of the intersectoral use intensities are then evaluated. The results could be summarized as follows: 


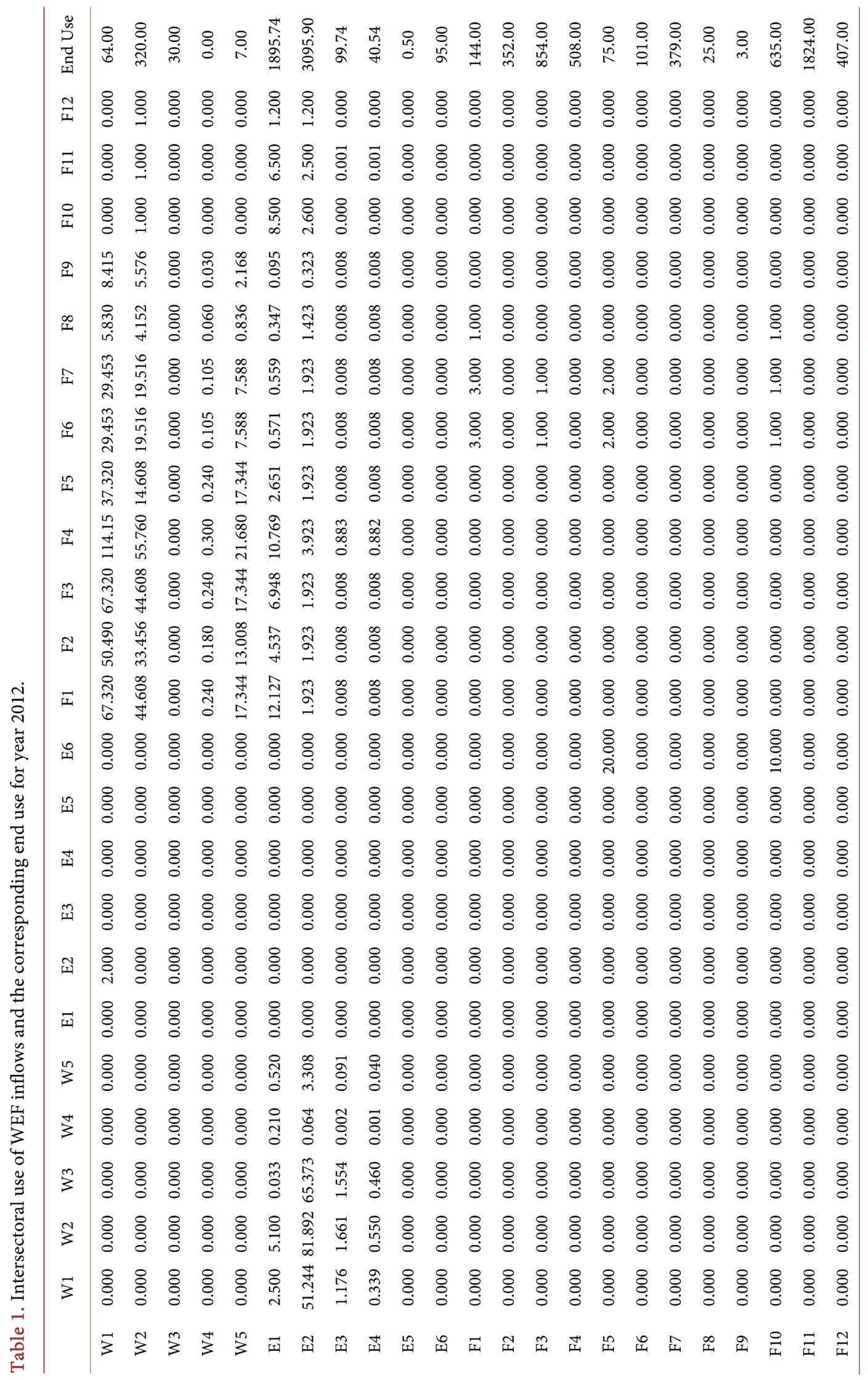


Table 2. Intensities of water use in energy and food inflows.

\begin{tabular}{|c|c|c|c|c|c|c|c|c|c|c|c|c|c|c|c|c|c|}
\hline E1 & $\mathrm{E} 2$ & E3 & E4 & E5 & E6 & $\mathrm{F} 1$ & $\mathrm{~F} 2$ & F3 & $\mathrm{F} 4$ & F5 & F6 & F7 & F8 & F9 & F10 & F11 & F12 \\
\hline \multicolumn{6}{|c|}{$\left(\mathrm{m}^{3} /\right.$ toe $)$} & \multicolumn{12}{|c|}{$\left(\mathrm{m}^{3} / \mathrm{t}\right)$} \\
\hline 0 & 1 & 0 & & 0 & & 858 & 276 & 151 & 378 & 702 & 561 & 150 & 435 & 5396 & 2 & 1 & 2 \\
\hline
\end{tabular}

Table 3. Intensities of energy use in water and food inflows.

\begin{tabular}{|c|c|c|c|c|c|c|c|c|c|c|c|c|c|c|c|c|}
\hline W1 & W2 & W3 & W4 & W5 & $\mathrm{F} 1$ & F2 & F3 & $\mathrm{F} 4$ & F5 & F6 & F7 & F8 & F9 & F10 & F11 & F12 \\
\hline \multicolumn{5}{|c|}{$\left(\right.$ toe $\left./ \mathrm{Mm}^{3}\right)$} & \multicolumn{12}{|c|}{ (toe/Kt) } \\
\hline 116 & 158 & 2247 & 185 & 35 & 93 & 18 & 10 & 32 & 46 & 25 & 7 & 71 & 145 & 17 & 5 & 6 \\
\hline
\end{tabular}

Table 4. Intensities of food use in energy and food inflows.

\begin{tabular}{|c|c|c|c|c|c|c|c|c|c|c|c|c|c|c|c|c|c|}
\hline E1 & E2 & E3 & $\mathrm{E} 4$ & E5 & E6 & $\mathrm{F} 1$ & $\mathrm{~F} 2$ & F3 & F4 & F5 & F6 & F7 & F8 & F9 & F10 & F11 & $\mathrm{F} 12$ \\
\hline \multicolumn{6}{|c|}{ (t/Ktoe) } & \multicolumn{12}{|c|}{$(\mathrm{t} / \mathrm{Kt})$} \\
\hline 0 & 0 & 0 & 0 & 0 & 316 & 0 & 0 & 0 & 0 & 0 & 69 & 18 & 80 & 0 & 0 & 0 & 0 \\
\hline
\end{tabular}

Table 6. Projected water use intensities in food inflows $\left(\mathrm{m}^{3} / \mathrm{t}\right)$.

\begin{tabular}{cccccccccccc}
\hline F1 & F2 & F3 & F4 & F5 & F6 & F7 & F8 & F9 & F10 & F11 & F12 \\
\hline 685 & 220 & 130 & 310 & 562 & 561 & 150 & 435 & 5396 & 2 & 1 & 2 \\
\hline
\end{tabular}

Table 7. Projected energy use intensities in food inflows (toe/kt).

\begin{tabular}{cccccccccccc}
\hline F1 & F2 & F3 & F4 & F5 & F6 & F7 & F8 & F9 & F10 & F11 & F12 \\
\hline 195 & 40 & 25 & 65 & 92 & 25 & 7 & 71 & 145 & 17 & 5 & 6 \\
\hline
\end{tabular}

The output of food-related water consumption will decrease by $\Delta z^{w_{-} f}=$ 96.087 $\mathrm{Mm}^{3}$ which accounts for $8.11 \%$ decrease in water of the total water usage. This decrease in water consumption will lead to decrease in the output of the water-related energy consumption by 11.281 ktoe. Similarly, food-related energy consumption will have to increase its output by $\Delta z^{e_{-} f}=56.576$ ktoe which accounts for $1.02 \%$ increase in energy of the total energy usage. This increase in energy consumption will lead to increase in the output of the energyrelated water consumption by $0.0015 \mathrm{Mm}^{3}$. So, the evaluation of the considered scenario shows the amount of achieved water savings and the increase in energy usage, therefore, decision makers will be informed about the quantitative impacts when adopting this policy option.

\section{Conclusions and Further Developments}

The WEF nexus model presented in [1] performs simulation of scenarios that respond to quantitative variations of the end use of WEF resources. The simulation of policy options by considering the use of high efficient WEF intersectoral use technologies necessitates a methodological addition to the model. Therefore, a methodological approach to analyzing scenarios of adopting high efficient intersectoral use technologies is introduced. The proposed approach permits the 


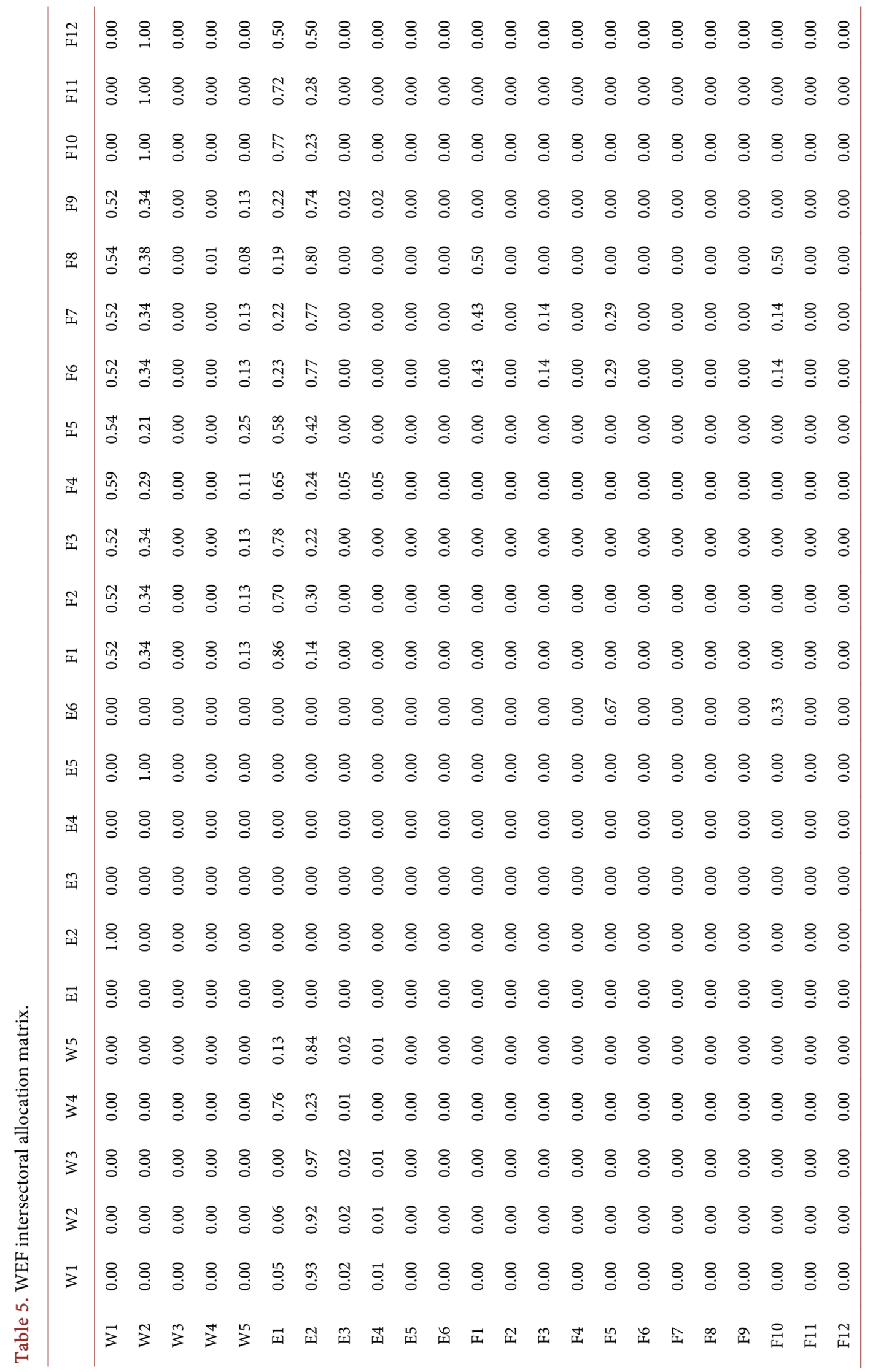




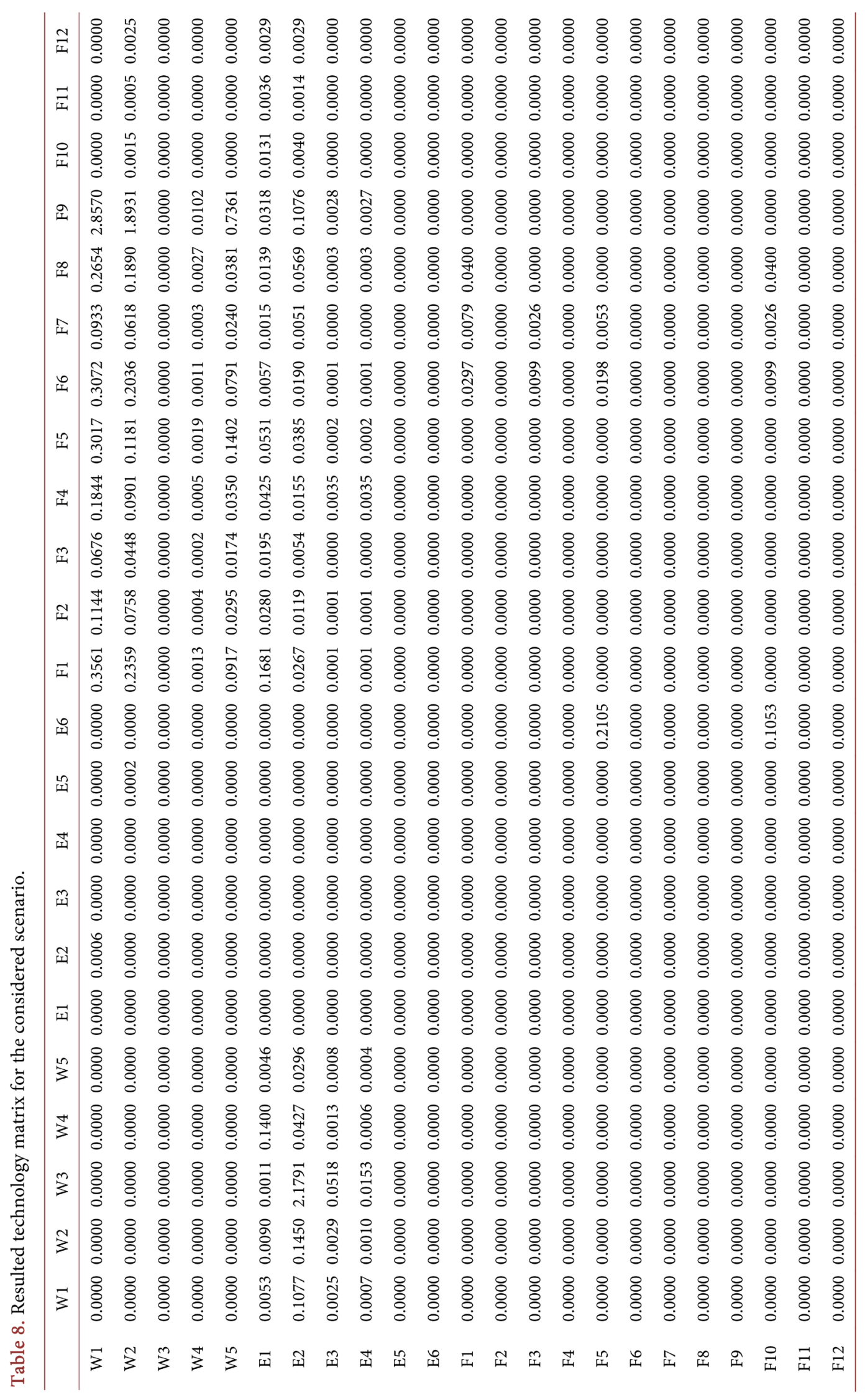


evaluation of the effects of a large number of possible WEF policy scenarios by taking advantages of best practice nexus technology matrices that are technologically most efficient. Two modeling variables are inserted into the technology matrix of the Q-Nexus Model: 1) the WEF intersectoral use intensities $(t)$ and 2) the WEF intersectoral allocation coefficients $(c)$.

The methodological amendment made on the Q-Nexus Model make it well suited to analyzing various technological, structural and quantitative changes scenarios:

1) It allows to analyzing scenarios of changing the technology matrix $(A)$ by considering "High Efficient" and "Best Practice" technology matrix alternatives. It permits also to evaluate the effects of the technology shifts for future development.

2) The construction of the WEF intersectoral allocation matrix $(C)$ allows considering "Optimized" intersectoral allocation matrix options which leads to considering "Optimized" technology matrix alternatives and calculating the resulted WEF quantities.

3) The proposed method permits interpreting the $A$ matrix to better understand the nexus forming and to compare different nexus systems with each other. Based on the origination of $(t)$ and (c), the $A$ matrix of the Q-Nexus Model totally befits to be a Nexus Matrix Code or fingerprinting matrix of a nexus system.

4) It allows analyzing and comparing when effects of additional demands are offset by effects of technology change.

5) Lastly, this approach will enhance the understanding of the complex and dynamic interrelationships between water, energy and food, and support the sustainable planning and management of these finite resources to ensure WEF security and access for all.

\section{References}

[1] Karnib, A. (2017) Quantitative Assessment Framework for Water, Energy and Food Nexus. Computational Water, Energy and Environmental Engineering, 6, 11-23. http://dx.doi.org/10.4236/cweee.2017.61002

[2] Technical University of Denmark (DTU) (2016) The Energy-Water-Food Nexusfrom Local to Global Aspects. International Energy Report 2016, DTU Web. http://www.natlab.dtu.dk/english/energy reports/dier 2016

[3] Hoff, H. (2011) Understanding the Nexus. Background Paper for the Bonn 2011 Conference: The Water, Energy and Food Security Nexus. Stockholm, Sweden: Stockholm Environment Institute (SEI).

[4] FAO (2011) Climate Change, Water and Food Security. FAO Water Reports No. 36. Food and Agriculture Organization of the United Nations, Rome.

[5] FAO (2014) The Water-Energy-Food Nexus-A New Approach in Support of Food Security and Sustainable Agriculture. Food and Agriculture Organization of the United Nations, Rome.

[6] Bizikova, L., Roy, D., Swanson, D., Venema, H.D. and McCandless, M. (2013) The Water-Energy-Food Security Nexus: Towards a Practical Planning and DecisionSupport Framework for Landscape Investment and Risk Management. IISD Report. Winnipeg, International Institute for Sustainable Development (IISD), Canada. http://www.iisd.org/pdf/2013/wef nexus 2013.pdf 
[7] Waskom, R., Akhbari, M. and Grigg, N. (2014) U.S. Perspective on the WaterEnergy-Food Nexus. Completion Report No.116, Colorado Water Institute.

[8] FAO (2013) An Innovative Accounting Framework for the Food-Energy-Water Nexus, Environment and Natural Resources Management. Working Paper No. 56, Food and Agriculture Organisation of the United Nations, Rome.

[9] FAO (2014) The Water-Energy-Food Nexus at FAO. Concept Note, Food and Agriculture Organisation of the United Nations, Rome.

[10] FAO (2014) Walking the Nexus Talk: Assessing the Water-Energy-Food Nexus in the Context of the Sustainable Energy for All Initiative. Food and Agriculture Organisation of the United Nations, Rome.

[11] ICIMOD (2012) Contribution of Himalayan Ecosystems to Water, Energy, and Food Security in South Asia: A Nexus Approach. International Centre for Integrated Mountain Development (ICIMOD), Kathmandu.

[12] UNECE, Task Force on Water-Food-Energy-Ecosystems (2013) Water-FoodEnergy-Ecosystems Nexus for Reconciling Different Uses in Transboundary River Basins-UNECE Water Convention Draft Methodology. United Nations Economic Commission for Europe, Geneva.

[13] Boelee, E., Hoa, E. and Chiramba, T. (2014) UNEP's Engagement in the WaterEnergy-Food Nexus. Bonn 2014 Conference, Sustainability in the Water-EnergyFood Nexus.

[14] Bizikova, L., Roy, D., Swanson, D., Venema, H.D. and McCandless, M. (2014) WaterEnergy-Food Nexus and Agricultural Investment: A Sustainable Development Guidebook, Winnipeg, Canada: International Institute for Sustainable Development (IISD). http://www.iisd.org/pdf/2014/WEF guidebook.pdf

[15] Andrews-Speed, P., Bleischwitz, R., Boersma, T., Johnson, C., Kemp, G. and VanDeveer, S.D. (2012) The Global Resource Nexus: The Struggles for Land, Energy, Food, Water, and Minerals. Transatlantic Academy, Washington DC.

[16] Biggs, E.M., Bruce, E., Boruff, B., Duncan, J.M.A., Horsley, J., Pauli, N., et al. (2015) Sustainable Development and the Water-Energy-Food Nexus: A Perspective on Livelihoods. Environmental Science \& Policy, 54, 389-397.

\section{Scientific Research Publishing}

\section{Submit or recommend next manuscript to SCIRP and we will provide best service for you:}

Accepting pre-submission inquiries through Email, Facebook, LinkedIn, Twitter, etc. A wide selection of journals (inclusive of 9 subjects, more than 200 journals)

Providing 24-hour high-quality service

User-friendly online submission system

Fair and swift peer-review system

Efficient typesetting and proofreading procedure

Display of the result of downloads and visits, as well as the number of cited articles

Maximum dissemination of your research work

Submit your manuscript at: http://papersubmission.scirp.org/

Or contact gep@scirp.org 